\title{
Assessing the ruminal action of the isopropyl ester of 2-hydroxy-4-(methylthio) butanoic acid in continuous and batch cultures of mixed ruminal microbes
}

\author{
C. M. Fowler, ${ }^{* 1}$ J. E. Plank, ${ }^{*}$ E. Devillard, $†$ B. J. Bequette, $\ddagger^{2}$ and J. L. Firkins ${ }^{* 3}$ \\ *Department of Animal Sciences, The Ohio State University, Columbus 43210 \\ †Adisseo Inc., 03600 Commentry, France \\ ‡Department of Animal and Avian Sciences, University of Maryland, College Park 20742.
}

\begin{abstract}
In dairy rations, Met is often a limiting amino acid that is provided by rumen-undegradable protein and rumen-protected sources of Met. A Met precursor, 2-hydroxy-4-(methylthio) butanoic acid (HMB) has undergone considerable study for ruminal and postruminal metabolism, whereas its isopropyl ester (HMBi) has been evaluated primarily with respect to its supply of metabolizable Met rather than as a preformed source of Met for microbial metabolism. A control and 3 isomolar Met treatments- $0.097 \%$ DL-Met, $0.048 \%$ DL-Met plus $0.055 \%$ HMBi (Met + HMBi treatment), and $0.11 \%$ $\mathrm{HMBi}$ - were pulse-dosed every $8 \mathrm{~h}$ into continuous cultures simultaneously with feeding. Treatment had no effect on digestibilities of acid-detergent fiber or true organic matter. Digestibilities of neutral detergent fiber and hemicellulose were linearly decreased with increasing HMBi inclusion. Concentration of $\mathrm{NH}_{3}-\mathrm{N}$ tended to decrease linearly and quadratically, and $\mathrm{NH}_{3}-\mathrm{N}$ flow tended to decrease linearly, with increasing HMBi inclusion; in contrast, the proportion of bacterial $\mathrm{N}$ derived from $\mathrm{NH}_{3}-\mathrm{N}$ increased linearly. Peptide $\mathrm{N}$ increased linearly and tended to be affected quadratically (highest for the HMBi treatment). Acetate and propionate production both decreased with increasing HMBi, but acetate declined more such that acetate:propionate increased linearly. Isobutyrate production decreased, but isovalerate and valerate increased with increasing HMBi inclusion. Relative changes in population abundance were not detected by denaturing gradient gel electrophoresis. In the second study, which was done in batch culture, Met treatments consisted of control, $0.097 \%$ L-Met, $0.097 \%$ L-Met, $0.125 \%$ DL-HMBi, $0.098 \%$ DL-HMB, $0.250 \%$ DL-HMBi $(2 \times \mathrm{HMBi}), 0.049 \%$ DLMet $+0.063 \%$ DL-HMBi (Met $+\mathrm{HMBi})$, and $0.098 \%$
\end{abstract}

Received August 1, 2014.

Accepted September 25, 2014.

${ }^{1}$ Current address: Provimi North America, Lewisburg, OH 45338.

${ }^{2}$ Deceased.

${ }^{3}$ Corresponding author: firkins.1@osu.edu
DL-HMB $+0.039 \%$ isopropanol. All of these Met treatments were unlabeled (i.e., at natural abundance of ${ }^{13} \mathrm{C}$ ) but simultaneously dosed with equivalent dosages of $\left[1-{ }^{13} \mathrm{C}\right]-\mathrm{L}-\mathrm{Met}$. All 8 treatments were inoculated with faunated or partially defaunated inocula. Protozoal abundance had minor effect on measurements. The unlabeled L-Met treatment had the lowest ${ }^{13} \mathrm{C}$ enrichment of Met in the microbial pellet followed by Met $+\mathrm{HMBi}$ and then D-Met or DL-HMB, which were lower than remaining treatments. The percentage of the $\left[1-{ }^{13} \mathrm{C}\right]$ L-Met dose recovered in microbial Met was lowest for the L-Met treatment; intermediate for D-Met, DL-HMB (with or without isopropanol), and Met + HMBi treatments; and highest for HMBi, $2 \times \mathrm{HMBi}$, and control. Results suggest that racemization of D-Met lags behind L-Met. The similar conversions of the HMBi and $2 \times$ HMBi treatments compared with the control suggests a low degradation of HMBi to provide unlabeled Met to dilute the $\left[1-{ }^{13} \mathrm{C}\right]$-L-Met dose for protein synthesis. The lack of treatment by time interaction suggests that these initial responses carried through during the 24 $\mathrm{h}$ of incubation. The proportion of HMBi available to ruminal microbes can influence microbial metabolism, potentially through formation of L-Met.

Key words: methionine, hydroxymethylthiobutanoic acid, microbial protein synthesis

\section{INTRODUCTION}

The isopropyl ester (HMBi) of 2-hydroxy4-(methylthio) butanoic acid (HMB) has increased total milk production, FCM production, and true milk protein relative to HMB (St-Pierre and Sylvester, 2005). Despite increasing the escape and postruminal supply of this Met precursor, a proportion of HMBi is hydrolyzed to HMB for ruminal degradability or possibly absorption from the rumen or omasum (Noftsger et al., 2005). Increasing HMB decreased the proportion of bacterial $\mathrm{N}$ derived from $\mathrm{NH}_{3}-\mathrm{N}$ in continuous culture while increasing concentration of isobutyrate and decreasing propionate, and HMB increased ADF di- 
gestibility relative to isomolar DL-Met (Noftsger et al., 2003). Because of the continuous infusion of the HMB in that study, we reasoned in the current study that infrequent pulse-dosing of the more slowly available form, $\mathrm{HMBi}$, would sustain ruminally available Met and therefore increase efficiency of microbial protein synthesis. In addition to the recognized role of AA to stimulate growth of amylolytic bacteria, AA also might stimulate fibrolytic bacteria (Firkins et al., 2007). Both $\mathrm{HMB}$ and HMBi increased 16S rRNA gene copies of the cellulolytic bacteria, Fibrobacter succinogenes and Ruminococcus flavefaciens, presumably through increased availability of Met (Martin et al., 2013). Our first objective was to assess the dose response of HMBi when replacing DL-Met in continuous culture to assess the amount and efficiency of bacterial protein synthesis, fermentation profile, and fiber digestibility.

A second study investigated factors influencing HMBi metabolism by ruminal microbes in batch culture. Alcohols such as isopropanol (from ester hydrolysis of $\mathrm{HMBi}$ ) can promote leakage of cellular contents through bacterial membranes (Ezeji et al., 2010) or can detach bacteria from feed particles (TrabalzaMarinucci et al., 2006). Although the effect of the isopropanol released from HMBi is unknown (Martin et al., 2013), alcohols are common in silages (Kristensen et al., 2007) and isopropanol might even be produced by some rumen microbes (Sato and Shiogama, 2010). Little is known about rumen microbial metabolism of D-Met and D-HMB relative to their more biologically active L-stereoisomers. Because total DL-Met degradation is so extensive (Hegedüs et al., 1995; Bach and Stern, 1999), D-Met presumably would be extensively rapidly racemized. Similarly, HMB is an approximately racemic mixture of stereoisomers (Lobley et al., 2006). Transport of L-Met into the cytoplasm in Escherichia coli is much more efficient because of its greater affinity compared with that of D-Met (Zhang et al., 2003). Slower D-Met transport into the cytoplasm could localize it in the periplasm for racemization. However, both D-Met and D-Leu, which are not traditionally thought of as components of peptidoglycan (as is D-Ala, most notably), are produced in periplasm and have important sensing and signaling roles in cell wall synthesis and remodeling of various bacterial strains tested (Lam et al., 2009; Cava et al., 2011). Although nonspecific transport and conversion of D-HMB has been characterized for animal tissues (Martín-Venegas et al., 2011), mitochondria (the main cellular compartment for DHMB metabolism) typically are not expressed in ruminal microbes. Ruminal protozoa express hydrogenosomes, which are likely adaptations from mitochondria by anaerobic eukaryotes (Hackstein and Tielens, 2010), so HMB metabolism might be prioritized in protozoa
(Noftsger et al., 2005). Whereas D-stereoisomers are detected in rumen bacteria (Schieber et al., 1999), little is known specifically about D-Met or D-HMB metabolism for rumen microbes. Consequently, the aim of the second experiment was to directly assess the role of isopropanol and the D-Met stereoisomer compared with DL-HMB and DL-HMBi through controlled additions to batch cultures of mixed ruminal microbes from 2 inocula sources that have low or higher concentrations of protozoa.

\section{MATERIALS AND METHODS}

\section{Experiment 1: Experimental Design, Sampling, and Analyses}

A dual-flow continuous culture fermentation system (Noftsger et al., 2003) was used in a $4 \times 4$ Latin square. The 4 periods lasted $12 \mathrm{~d}$, with the first $8 \mathrm{~d}$ for adaptation. Ruminal contents were collected from 2 multiparous lactating Holstein cows receiving a normal lactation diet, squeezed through 8 layers of cheesecloth, sealed tight to minimize access to air, and transported to the laboratory in an insulated container previously warmed to $39^{\circ} \mathrm{C}$. After inoculation into fermenters, artificial saliva was infused to maintain liquid and solids dilution rates of 12.5 and $5.5 \% / \mathrm{h}$, respectively. The $\mathrm{pH}$ was maintained between 6.0 and 7.0, and temperature was kept constant at $39 \pm 1^{\circ} \mathrm{C}$. The fermentation vessels varied in measured working volume from approximately 1,600 to $1,835 \mathrm{~mL}$, so DM input was varied proportionately (averaging $100.0 \mathrm{~g} / \mathrm{d}$, ranging from 94.3 to $108.2 \mathrm{~g} / \mathrm{d}$ ) to maintain a constant volume-to-DM ratio. The diets were 50:50 forage:concentrate and fed in 3 equal meals per day at 0000, 0800, and $1600 \mathrm{~h}$. The diet composition is shown in Table 1 and was formulated without soybean meal to complement RDP in alfalfa to prevent excessive RDP from potential responses to Met supplementation. Although the CP and RDP were lower than in typical diets, the buffer provided urea at $0.4 \mathrm{~g} / \mathrm{L}$. With an average of $5.1 \mathrm{~L} / \mathrm{d}$ of buffer outflow, the urea- $\mathrm{N}$ provided an equivalent of $>5 \%$ unit $\mathrm{CP}$ and RDP to the diets, which averaged $100 \mathrm{~g} / \mathrm{d}$ of DMI input (data not shown). The treatments contained no supplement, 0.097\% DL-methionine (DL-Met treatment designation), $0.048 \%$ DL-Met plus 0.055\% HMBi (Met + HMBi), or $0.11 \%$ HMBi (HMBi treatment). The amounts of $\mathrm{HMBi}$ and DL-Met were chosen from the previous continuous culture study of Noftsger et al. (2003). The supplements and control were provided at $3.6 \mathrm{~mL}$ of liquid directly into the fermentation vessels at each feeding with overflow halted to allow mixing.

On d 10, 11, and 12, a $15 \%$ sample of the total effluent (liquid and solid) was taken and composited. The 
Table 1. Ingredient and chemical composition in Experiments 1 and 2

\begin{tabular}{lc}
\hline Ingredient composition & $\% \mathrm{DM}$ \\
\hline Alfalfa pellets & 50.00 \\
Pelleted concentrate & 31.00 \\
Corn grain, ground & 6.50 \\
Dry distillers grain & 0.50 \\
Blood meal, ring-dried & 10.80 \\
Soybean hulls $_{\text {CaPO }}$ & 0.33 \\
Limestone $_{\text {MgO }}$ & 0.065 \\
Trace mineralized salt & 0.13 \\
Vitamins A, D, and $\mathrm{E}^{2}$ & 0.50 \\
Chemical composition & 0.104 \\
NDF & 34.9 \\
ADF & 23.6 \\
CP & 14.2 \\
RDP & 7.9 \\
\hline
\end{tabular}

${ }^{1}$ Contained $0.10 \% \mathrm{Mg} ; 38.08 \% \mathrm{Na} ; 58.0 \% \mathrm{Cl} ; 0.04 \% \mathrm{~S} ; 5.000 \mathrm{mg} / \mathrm{kg}$ of $\mathrm{Fe} ; 7,500 \mathrm{mg} / \mathrm{kg}$ of $\mathrm{Zn} ; 2,500 \mathrm{mg} / \mathrm{kg}$ of $\mathrm{Cu} ; 6,000 \mathrm{mg} / \mathrm{kg}$ of $\mathrm{Mn} ; 100$ $\mathrm{mg} / \mathrm{kg}$ of I; $60 \mathrm{mg} / \mathrm{kg}$ of Se; and $50 \mathrm{mg} / \mathrm{kg}$ of Co.

${ }^{2}$ Vitamin premixes: $0.012 \%$ of vitamin A $(30,000 \mathrm{IU} / \mathrm{g}), 0.033 \%$ of vitamin $\mathrm{D}(3,000 \mathrm{IU} / \mathrm{g})$, and $0.059 \%$ of vitamin $\mathrm{E}(20,000 \mathrm{IU} / 454 \mathrm{~g})$.

${ }^{3}$ Rumen-degraded protein from NRC (2001) library values.

3-d composite sample was lyophilized and analyzed for $\mathrm{ADF}$ (AOAC, 1990) and for NDF in the presence of heat-stable $\alpha$-amylase and sodium sulfite (Van Soest et al., 1991). Hemicellulose was calculated as NDF ADF. For each of the $3 \mathrm{~d}$, a $47-\mathrm{mL}$ aliquot of the effluent sample was acidified with $3 \mathrm{~mL}$ of $6 \mathrm{~N} \mathrm{HCl}$ to stop fermentation, and all the samples were composited. The composited sample was analyzed for VFA using gas chromatography (Harvatine et al., 2002) and for ammonia-N by the colorimetric method of Chaney and Marbach (1962). Bacteria were pelleted from a total effluent (liquid and solid) sample of the 3-d composite (Karnati et al., 2009a). Nitrogen and OM concentration were determined for effluent and lyophilized bacteria by micro-Kjeldahl (AOAC, 1990). We infused $\left(\mathrm{NH}_{4}\right)_{2} \mathrm{SO}_{4}$ that was $10 \%$ enriched with ${ }^{15} \mathrm{~N}$, samples were collected and analyzed for ${ }^{15} \mathrm{~N}$ enrichment for $\mathrm{NH}_{3}-\mathrm{N}$ and bacterial $\mathrm{N}$, and bacterial $\mathrm{N}$ flow and bacterial $\mathrm{N}$ derived from $\mathrm{NH}_{3}-\mathrm{N}$ were calculated as described by Noftsger et al. (2003).

\section{Denaturing Gradient Gel Electrophoresis Analysis of Bacteria (Experiment 1)}

Three 15-mL samples of total effluent were taken between 31.5 and $41 \mathrm{~h}$ as described in another manuscript from our laboratory (Firkins et al., 2015). These samples were stored at $-80^{\circ} \mathrm{C}$. After thawing, $1.5 \mathrm{~mL}$ was aliquoted for DNA extraction, with minor changes compared with the procedures described by $\mathrm{Yu}$ and Morrison (2004) and Karnati et al. (2009b). Briefly, 2 rounds of bead-beating were done to break the cells, then nucleic acid precipitation, treatment with RNase
A and proteinase $\mathrm{K}$, and column purification were also carried out. The V3 region of $16 \mathrm{~S}$ rRNA gene was amplified using primers 357f-GC (synthesized with a 40-bp GC clamp at its 5' end) and 519r. The amplification reactions were comprised of $100 \mathrm{pmol}$ of each primer, $250 \mu M$ dNTP, $2 \mathrm{~m} M$ magnesium chloride, $0.05 \%$ bovine serum albumin, $1 \times$ PCR buffer, and 5.0 units of Platinum Taq DNA polymerase (Invitrogen, Carlsbad, CA) in $50 \mu \mathrm{L}$. A hot-start thermocycling program was used as follows: initial denaturation at $94^{\circ} \mathrm{C}$ for $5 \mathrm{~min}$; 10 touchdown cycles at $94^{\circ} \mathrm{C}$ for $30 \mathrm{~s}$, then the annealing temperature decreased from $61^{\circ} \mathrm{C}$ to $56^{\circ} \mathrm{C}$ by $0.5^{\circ} \mathrm{C} /$ cycle, followed by an extension step at $72^{\circ} \mathrm{C}$ for $30 \mathrm{~s}$; then 25 cycles with denaturation at $94^{\circ} \mathrm{C}$ for $30 \mathrm{~s}$, annealing at $56^{\circ} \mathrm{C}$ for $30 \mathrm{~s}$, and extension at $72^{\circ} \mathrm{C}$ for $1 \mathrm{~min}$; and the program ended with a final $72^{\circ} \mathrm{C}$ extension for $30 \mathrm{~min}$. The $\mathrm{PCR}$ reaction included negative and positive controls. The PCR product was approximately $200 \mathrm{bp}$, as verified by electrophoresis in a 1\% agarose gel. The PCR products were resolved on a $7.5 \%$ polyacrylamide gel $(37.5: 1)$ with a 40 to $70 \%$ denaturing gradient for $1,600 \mathrm{~V} \cdot \mathrm{h}$. The gel was stained with SYBR green and visualized with a Gel Logic 1500 imager (Kodak, New Haven, CT). The TIFF images were imported, and cluster analysis was performed as per Karnati et al. (2009b).

\section{Experiment 2: Batch Culture Incubation of Met and HMBi Derivatives}

The second experiment apportioned the potential sources of variation associated with HMBi metabolism by ruminal microbes in batch culture, which prevented passage of undegraded HMBi or HMB. Treatments consisted of (1) an unsupplemented control, (2) 0.097\% L-Met, (3) $0.097 \%$ D-Met, (4) $0.125 \%$ DL-HMBi, (5) $0.098 \%$ DL-HMB, (6) $0.250 \%$ DL-HMBi $(\mathbf{2} \times \mathbf{H M B i})$, (7) $0.049 \%$ DL-Met $+0.063 \%$ DL-HMBi, and (8) $0.098 \%$ DL-HMB $+0.039 \%$ isopropanol. The CON, HMBi, and Met + HMBi treatments were designed to be similar to those in experiment 1 . With the exception of the control and $2 \times$ HMBi treatments, the inclusion rate for other treatments was isomolar as a percentage of the diet DM. Inclusion rates for Met $+\mathrm{HMBi}$ combined are isomolar with single treatments of Met or Met analogs. The $2 \times$ HMBi inclusion was chosen assuming 50\% escape of $\mathrm{HMBi}$ relative to L-Met (i.e., predicted to be isomolar on a metabolized basis as in Martin et al., 2013).

\section{Inoculating Fermenters for Usage as Inoculum in Batch Culture (Experiment 2)}

Ruminal fluid was maintained in continuous culture for adaptation and subsequent inoculation in batch 
culture to better mimic results from experiment 1 and, second, to wash protozoa out of faunated fermenters to prepare partially defaunated inoculum with minimal effect on the prokaryotic communities. Approximately $2.5 \mathrm{~L}$ of rumen fluid were collected from each of $2 \mathrm{Hol}-$ stein cows (5 L total) and processed as described for experiment 1. The fermenters were fed $40 \mathrm{~g} / \mathrm{d}$ of a 50:50 mixture of alfalfa and concentrate pellets as described by Karnati et al. (2009a), except that fluid and solids dilution rates were set to 7 and $5 \% / \mathrm{h}$, respectively. In the first fermenter, the agitation paddles were set to 50 RPM, and the protozoa were retained using a compound filter that consisted of a $50-\mu \mathrm{m}$ filter wrapped in layers of nylon cotton. In the second fermenter, the agitation paddles were set to $160 \mathrm{RPM}$, and the protozoa were primarily effluxed using a wire mesh filter with a pore size of $300 \mu \mathrm{m}$. These preincubations were repeated the same for the second replication of the batch culture experiment except that an extra day ( 8 vs. 7 d) was used to preincubate fermenter contents before inoculation of $50-\mathrm{mL}$ batch culture tubes. On the day of the inoculation (corresponding with $0 \mathrm{~h}$ of incubation in batch culture), samples of fermenter vessel liquids were taken, fixed in formalin, and counted (Dehority, 1984).

A total of $0.5 \mathrm{~g}$ of feed $(0.25 \mathrm{~g}$ of each crushed alfalfa pellets and crushed concentrate pellets that were used in experiment 1) were weighed into $50-\mathrm{mL}$ centrifuge tubes. On the morning of the inoculation, treatments were dissolved in distilled water and dosed into the appropriate tubes. In addition to the various treatments, all tubes were also dosed with isomolar concentrations of treatments that were based on doses in experiment 1. To all tubes were added $0.33 \mu \mathrm{mol}$ of $\left[1-{ }^{13} \mathrm{C}\right]-\mathrm{L}-\mathrm{Met}$ [98\% purity, 99 atom percent excess (APE), Cambridge Isotopes, Andover, MA] and $0.118 \mathrm{mg} /$ tube of $10 \%$ enriched $\left({ }^{15} \mathrm{NH}_{4}\right)_{2} \mathrm{SO}_{4}$ (Isotec Inc., Miamisburg, $\mathrm{OH}$ ). For comparison purposes, the total dosage of the unlabeled L-Met treatment was predicted to dilute the $\left[1-{ }^{13} \mathrm{C}\right]-\mathrm{L}-$ Met to $10.2 \mathrm{APE}$, whereas the ${ }^{15} \mathrm{NH}_{3}$ was diluted by $\mathrm{NH}_{3}$ in the inocula to approximately $0.08 \mathrm{APE}$. The large difference in APE minimized interference in analysis of ${ }^{13} \mathrm{C}$-enriched Met. Fermenter vessels were sampled before inoculation to record the density of protozoa in each inoculum. These steps were repeated in the second replication, which served as a block.

Fermenter liquid from each vessel was mixed with an equal volume of fresh media solution (no additional cysteine was added to media solution), passed through 2 layers of cheesecloth into 2 separate vessels and warmed in a hot water bath to $39^{\circ} \mathrm{C}$ while bubbling with $\mathrm{CO}_{2}$. Based on results from a pilot study, this dilution was needed to provide enough buffering capacity without over-diluting the microbes. While continually mixing by hand, $30 \mathrm{~mL}$ of the proper faunated or defaunated inoculum was added to the assigned batch culture tubes. The tubes were gassed with $\mathrm{CO}_{2}$, immediately capped with rubber stoppers with one-way valves, and swirled with continuous shaking or swirling. At appropriate times, tubes were uncapped, $1 \mathrm{~mL}$ of $6 \mathrm{~N} \mathrm{HCl}$ added to stop fermentation, and vortexed. Tubes were refrigerated until further processing.

\section{Measurements and Laboratory Analysis (Experiment 2)}

Two replicate tubes from each treatment/time point/ inocula were processed for ${ }^{13} \mathrm{C}$ enrichment of bacterial Met. Following low-speed centrifugation $\left(500 \times g\right.$ at $4^{\circ} \mathrm{C}$ for $15 \mathrm{~min}$ ) to remove particulate matter and protozoa, the remaining bacterial pellet was precipitated $(20,000$ $\times g, 4^{\circ} \mathrm{C}, 15 \mathrm{~min}$ ) and washed 3 times with $0.9 \%$ (wt/ vol) saline solution, lyophilized, and stored at $-10^{\circ} \mathrm{C}$. Samples were shipped on ice to the University of Maryland for determination of bacterial ${ }^{13} \mathrm{C}-\mathrm{Met}$ enrichment (Firkins et al., 2015).

Unfortunately, free Met in the supernatant was destroyed more than expected by the addition of $6 \mathrm{~N} \mathrm{HCl}$ that was added to each tube to halt the fermentation during processing. Therefore, we could not use productto-precursor ${ }^{13} \mathrm{C}$ enrichment ratios to calculate bacterial Met originating from preformed Met. Further, the microbial pellet was contaminated by an unknown, but presumably minor, quantity of feed from particulate matter that could not be removed using standard filtering and differential centrifugation techniques. Consequently, we estimated microbial $\mathrm{N}$ and Met kinetics using the following approach:

$$
\begin{gathered}
\text { total NAN }- \text { feed } \mathrm{N}=\text { total microbial } \mathrm{N}(\mathrm{mg}) \\
{[1]-\text { blank total NAN }=} \\
\text { incremental microbial } \mathrm{N}(\mathrm{mg})
\end{gathered}
$$

Feed $\mathrm{N}$ was estimated by incubating each feed for 0 , 2,8 , and $24 \mathrm{~h}$ in situ (the same length of time of incubation in vitro in the current study) and determining the percentage of original feed $\mathrm{N}$ remaining at each time point. This percentage was multiplied by the amount of feed $\mathrm{N}$ added to the batch cultures to estimate feed $\mathrm{N}$ at respective times. The total NAN in the tubes minus the estimated undegraded feed $\mathrm{N}$ was used to estimate the amount of microbial $\mathrm{N}$ in the tubes in equation [1]. We recognize that [1] has some $\mathrm{N}$ from microbial and small particulate matter from the inocula. Small undegraded feed sources are needed for preparation of robust inoculum (Firkins, 1997). Incremental microbial $\mathrm{N}$ (equation [2]) was calculated as microbial $\mathrm{N}$ at 2, 8, 
and $24 \mathrm{~h}$ minus the microbial $\mathrm{N}$ in blank tubes from the corresponding time points. We note that these calculations subtract microbial $\mathrm{N}$ at zero time but also any particulate $\mathrm{N}$ from the inocula. Therefore, results from equation [2] are probably more accurate than those from equation [1]; however, results from [2] are less precise because errors accumulated from both samples (substrate added) and blanks (substrate not added). We recognize a greater potential for inaccuracy and higher error introduced in this approach, but resultant sample availability prevented chemical analysis, and microbial AA profile is relatively constant among treatments (Clark et al., 1992) even though $\mathrm{N}$ and nucleic acid concentration do vary (Firkins et al., 2006).

Total and incremental microbial (bacteria + protozoa) Met was calculated from equations [1] and [2], respectively, using published estimates. Protozoal and bacterial $\mathrm{N}$ (17.7 and $82.3 \%$ of microbial $\mathrm{N}$ ) were taken from a fermenter study maintained similarly to our inocula (Karnati et al., 2009a). The total AA from protozoal and bacterial samples ( 80.7 and $70.9 \%$ of total CP; $\mathrm{CP}=\mathrm{N} \times 6.25)$ and percentage of Met in the total AA for protozoal and bacterial samples (2.2 and $2.0 \%$ of total recovered AA) were averaged from different treatments within 3 published sources (Volden et al., 1999; Korhonen et al., 2002; Jensen et al., 2006) for protozoa and bacteria, respectively. Microbial Met in the incubation tubes could then be calculated using equations [1] for total or [2] for incremental microbial $\mathrm{N}$ as

[1] $\times($ protozoal N/microbial N) $\times($ protozoal total AA/protozoal N $) \times($ protozoal Met/protozoal total AA $)=$ protozoal Met $(\mathrm{mg})$;

$[2] \times($ protozoal $\mathrm{N} /$ microbial $\mathrm{N}) \times($ protozoal total AA/protozoal N) $\times($ protozoal Met/protozoal total AA) = incremental protozoal Met $(\mathrm{mg})$;

[1] $\times($ bacterial $\mathrm{N} /$ microbial $\mathrm{N}) \times($ bacterial total

$$
\begin{gathered}
\mathrm{AA} / \text { bacterial } \mathrm{N}) \times(\text { bacterial Met } / \text { bacterial } \\
\text { total } \mathrm{AA})=\text { bacterial Met }(\mathrm{mg}) ;
\end{gathered}
$$

$[2] \times($ bacterial $\mathrm{N} /$ microbial $\mathrm{N}) \times($ bacterial total AA/bacterial N) $\times($ bacterial Met/bacterial total $\mathrm{AA})=$ incremental bacterial Met $(\mathrm{mg})$;

$$
\text { protozoal Met [3] + bacterial Met [5] = }
$$
total microbial Met (mg); incremental protozoal Met [4] + incremental bacterial

$$
\begin{gathered}
\text { Met }[6]=\text { incremental microbial Met; } \\
{[7] \times \text { APE of }{ }^{13} \mathrm{C} \text { Met in pellet }=} \\
\text { microbial }{ }^{13} \mathrm{C} \text {-Met }(\mathrm{mg}) ; \\
{[8] \times \text { APE of }{ }^{13} \mathrm{C} \text { Met in pellet }=} \\
\text { incremental microbial }{ }^{13} \mathrm{C}-\text { Met }(\mathrm{mg}) ; \\
{[9] /{ }^{13} \mathrm{C} \text {-Met dosed }(\mathrm{mg}) \times 100=}
\end{gathered}
$$

microbial Met derived from dose (\%); and

$$
\begin{gathered}
{[10] /{ }^{13} \mathrm{C}-\text { Met dosed }(\mathrm{mg}) \times 10=\text { incremental }} \\
\text { microbial Met derived from dose }(\%)
\end{gathered}
$$

\section{Statistical Analysis (Experiments 1 and 2)}

Data from the first experiment (continuous culture) were analyzed using Proc MIXED of SAS (Cary, NC) for a $4 \times 4$ Latin square design. The effect of fermenter was a random effect, and period was considered a fixed effect to allow convergence of the mixed model. The first preplanned orthogonal contrast compared the average of all the Met treatments versus the control. Two additional contrasts were used to determine linear or quadratic response to DL-Met, Met $+\mathrm{HMBi}$, and HMBi.

Data from the second experiment were analyzed as a randomized complete block with $2 \times 8$ factorial arrangement of treatments using the Proc Mixed procedure of SAS, according to the following model:

$$
\begin{aligned}
\mathrm{Y}_{\mathrm{ijkl}}=\mu & +\mathrm{b}_{\mathrm{i}}+\mathrm{I}_{\mathrm{j}}+\mathrm{T}_{\mathrm{k}}+\mathrm{H}_{\mathrm{l}}+\mathrm{IT}_{\mathrm{ik}}+\mathrm{IH}_{j l} \\
& +\mathrm{TH}_{k l}+\mathrm{ITH}_{\mathrm{j} k l}+\mathrm{e}_{\mathrm{ijkl}},
\end{aligned}
$$

where $Y_{\mathrm{ijkl}}$ is the dependent, continuous variable; $\mu$ is the overall population mean; $b_{i}$ is the random effect of the ith block $(1 \mathrm{df}) ; \mathrm{I}_{\mathrm{j}}$ is the fixed effect of the jth inoculum $(1 \mathrm{df}) ; \mathrm{T}_{\mathrm{k}}$ is the fixed effect of the kth treatment ( $7 \mathrm{df}) ; \mathrm{H}_{1}$ is the fixed effect of the lth hour ( $\left.3 \mathrm{df}\right)$; $\mathrm{IT}_{\mathrm{jk}}$ is the fixed effect of the jth inoculum $\times$ kth treatment $(7 \mathrm{df}) ; \mathrm{IH}_{\mathrm{jl}}$ is the fixed effect of the jth inoculum $\times$ lth hour $(3 \mathrm{df}) ; \mathrm{TH}_{\mathrm{kl}}$ is the fixed effect of the kth treatment $\times$ lth hour $(21 \mathrm{df}) ; \mathrm{ITH}_{\mathrm{jkl}}$ is the fixed effect of the jth inoculum $\times$ kth treatment $\times$ lth hour $(21 \mathrm{df})$, $\mathrm{e}_{\mathrm{ijk} \mathrm{l}}$ is the residual error, assumed independent and [7] $\sim \mathrm{N}\left(0, \sigma_{e}^{2}\right),(63 \mathrm{df})$. 
Trichloroacetic acid-soluble $\mathrm{N}$, peptides, and $\mathrm{NH}_{3}$ data were analyzed with a covariate so that the dependent variables could be adjusted for the presence of the substances in blank tubes. When interactions were significant, differences among simple means were determined using Fisher's Protected LSD; when interactions were $P>0.10$, main effect means were compared with a protected LSD.

\section{RESULTS AND DISCUSSION}

\section{Experiment 1: Continuous Culture of DL-Met Replaced by DL-HMBi}

Nutrient Digestibility. Treatment did not affect $(P>0.10)$ ADF or true OM digestibilities (Table 2). Both NDF $(P=0.04)$ and hemicellulose $(P=0.01)$ digestibilities decreased linearly with increasing HMBi. Methionine and HMB supplementation have yielded inconsistent effects on nutrient digestibilities. Supplementation of $\mathrm{HMB}$ at 0.055 and $0.110 \%$ in continuous culture had no significant effect on digestibilities of hemicellulose, NDF, or true OM (Noftsger et al., 2003). Vázquez-Añón et al. (2001) noted no changes in true $\mathrm{OM}, \mathrm{NDF}, \mathrm{ADF}$, or NSC digestibilities associated with HMB, but HMB at 0.20 and $0.77 \%$ of $\mathrm{DM}$ (which are much higher than our HMBi dosage at $0.11 \%$ ) increased efficiency of microbial protein synthesis in continuous culture compared with their control or highest dose (1.43\%). Bach and Stern (1999) noted that high availability of Met from protein sources was associated with decreased degradability of some other AA. In our companion report that used $\left[1-{ }^{13} \mathrm{C}\right]$-L-Met kinetics, Firkins et al. (2015) noted that increasing HMBi apparently decreased Met uptake and degradation. Continuous culture systems such as ours have rapid stirring, which probably effluxes soluble protein faster than in the rumen. The extent of NDF digestibility is decreased (as is OM digestibility), but the variability is increased in continuous culture compared with total tract NDF or OM digestibilities (Hristov et al., 2012). Even removal of urea from the buffer decreased the degraded protein (without any change in diet) and $\mathrm{N}$ uptake of dietary $\mathrm{N}$ because of $\mathrm{N}$ limitation in continuous culture (Griswold et al., 2003). Those authors noted that hemicellulosedegrading bacteria were particularly stimulated by preformed $\mathrm{AA}$ ( 8 vs. $11 \% \mathrm{RDP}$ ) when $\mathrm{NH}_{3}-\mathrm{N}$ was limiting. Thus, HMBi might have decreased availability of AA for hemicellulose-degrading bacteria in our study because of the low amino N provided in the RDP (Table 1). Martin et al. (2013) noted that supplying HMB or HMBi increased abundance of cellulolytic bacteria in the rumen but not indices of NDF digestibility (enzyme activities and in situ disappearance). Thus, we consider it highly unlikely for NDF digestibility to be depressed by HMBi in vivo.

Table 2. Nutrient digestibilities, nitrogen fluxes, and nitrogen partitioning for rumen bacteria in continuous cultures supplemented with DL-Met, $\mathrm{HMBi}^{1}$, or both (Experiment 1)

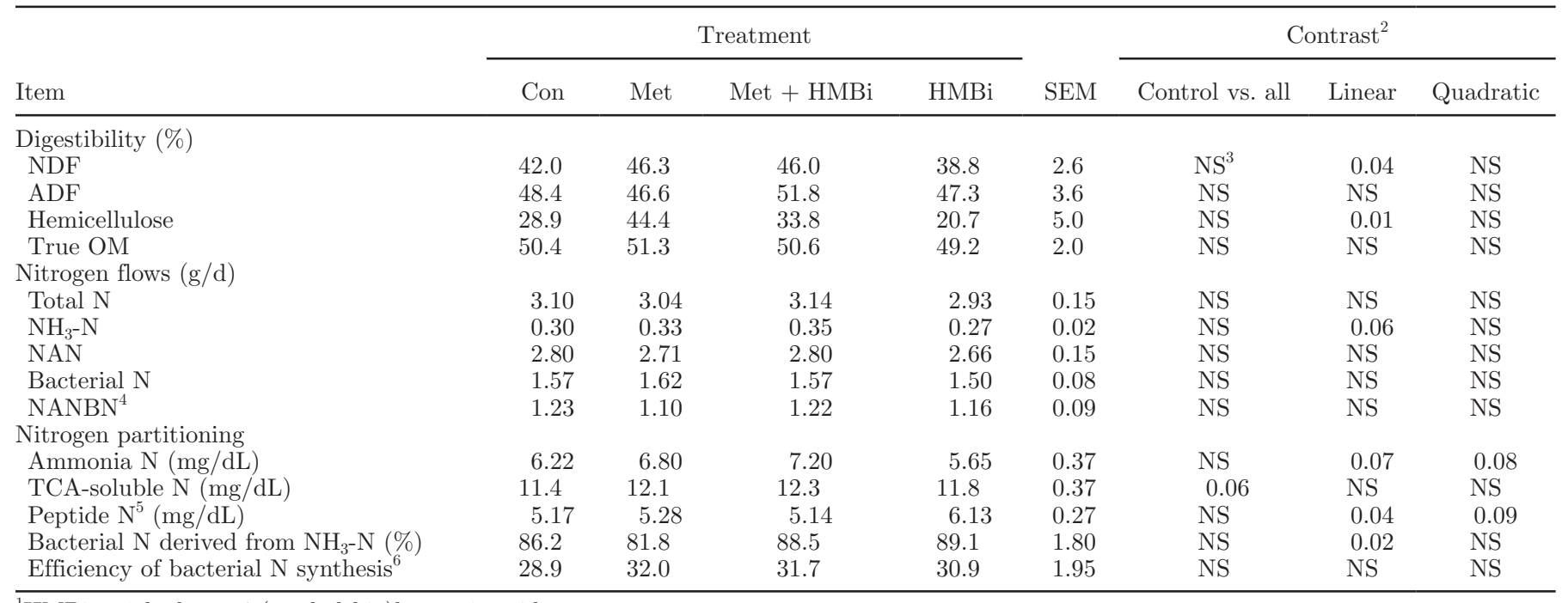

${ }^{1} \mathrm{HMBi}=2$-hydroxy-4-(methylthio)butanoic acid.

${ }^{2}$ All supplementation (HMBi, Met $\left.+\mathrm{HMBi}, \mathrm{MET}\right)$ vs. control, and linear and quadratic responses to the 3 supplements.

${ }^{3} \mathrm{NS}=$ not significant; $P>0.10$.

${ }^{4} \mathrm{NANBN}=$ nonammonia nonbacterial nitrogen $=\mathrm{NAN}-$ bacterial $\mathrm{N}$.

${ }^{5}$ Nitrogen soluble in $10 \%$ ( $\left.\mathrm{vol} / \mathrm{vol}\right)$ TCA.

${ }^{6}$ Grams of microbial N produced/kilograms of OM truly digested. 
Partitioning of $\boldsymbol{N}$. The flows of NAN, bacterial $\mathrm{N}$, total $\mathrm{N}$, and nonammonia nonbacterial $\mathrm{N}$ in the effluent were not different by treatment (Table 2). Flow of $\mathrm{NH}_{3}-\mathrm{N}$ tended $(P=0.06)$ to decrease linearly with increasing HMBi replacement of Met, although the quadratic contrast approached significance $(P=$ $0.11)$. The concentration of $\mathrm{NH}_{3}-\mathrm{N}$ tended to be affected linearly $(P=0.07)$ and quadratically $(P=0.08)$, mostly because $\mathrm{HMBi}$ numerically decreased $\mathrm{NH}_{3}-\mathrm{N}$ concentration compared with DL-Met or Met + HMBi. The $\mathrm{NH}_{3}-\mathrm{N}$ approached minimal optimum levels of 2 to $5 \mathrm{mg} / \mathrm{dL}$ (Hoover, 1986). Methionine supplementation increased $\mathrm{NH}_{3}-\mathrm{N}$ flow in continuous culture in another study (Bach and Stern, 1999). Ammonia concentration was increased by HMB replacement of DL-Met in continuous culture (Noftsger et al., 2003) but was not affected by increased HMB addition when no Met was substituted (Vázquez-Añón et al., 2001). For the concentration of TCA-soluble $\mathrm{N}$, which includes $\mathrm{NH}_{3} \mathrm{~N}$ and amino-N (including small peptides and free AA), the control tended $(P=0.06)$ to be less than the average of the other 3 treatments. However, peptide-N (which also contains free AA) increased linearly $(P$ $=0.04)$ and tended to be affected quadratically $(P$ $=0.09)$, this time with HMBi numerically having the highest peptide concentration (opposite of $\mathrm{NH}_{3}-\mathrm{N}$ ). The percentage of bacterial $\mathrm{N}$ derived from $\mathrm{NH}_{3}-\mathrm{N}$ increased $(P=0.02)$ as HMBi replaced Met. Thus, HMBi supplementation seems to decrease peptide degradation or decrease preference for preformed amino- $\mathrm{N}$, which is contrary to our original hypothesis. The concentrations of peptide $\mathrm{N}$ for all treatments were greater than those reported by Griswold et al. (2003), who used similar procedures and had higher percent of RDP in their diets. In our companion report (Firkins et al., 2015), we provide supportive evidence for accumulation of Met and potentially other AA in the fermenter medium with increasing HMBi inclusion.

Efficiency of bacterial protein synthesis was not affected by treatment (Table 2). Bacterial $\mathrm{N}$ flow and the efficiency of microbial protein synthesis were not affected by supplementation of Met (Bach and Stern, 1999) or HMB (Noftsger et al., 2003). In contrast, increasing dosages of HMB quadratically affected bacterial efficiency (Vázquez-Añón et al., 2001), with increasing efficiency at middle HMB doses (higher than typically fed).

VFA Production. Total VFA production was decreased linearly $(P=0.02)$ with increasing HMBi replacement of Met, primarily resulting from decreased acetate $(P=0.06)$ and propionate $(P<0.01$; Table $3)$. Propionate also was affected quadratically $(P=$ 0.05 ). Because propionate was affected proportionately greater, the acetate-to-propionate ratio tended to be af- fected linearly $(P=0.08)$ and quadratically $(P=0.06)$, indicating increasing ratios for both Met $+\mathrm{HMBi}$ and for HMBi treatments than for the DL-Met treatment. Butyrate and branched-chain VFA were not affected by treatment. Isobutyrate decreased linearly $(P=0.05)$ with increasing $\mathrm{HMBi}$, although isobutyrate was numerically greater for DL-Met and Met + HMBi than the control treatment. Isovalerate tended $(P=0.08)$ to increase linearly with increasing HMBi. The control was lower $(P=0.01)$ than the average of the other 3 treatments for valerate, which increased linearly $(P<$ 0.01 ) but plateaued (quadratic response, $P=0.05$ ) with increasing HMBi substitution for DL-Met. Part of the decreased acetate and propionate can be explained by increasing valerate (condensation of acetate and propionate) with increasing HMBi. Glucose fermentation to valerate consumes 1 net pair of electrons and protons (1 set of reducing equivalents) versus propionate's consumption of 2 sets of reducing equivalents per mole of glucose, whereas acetate is a net producer of 2 sets of reducing equivalents (Russell and Wallace, 1988). In addition, reducing equivalents can be consumed during $\mathrm{NH}_{3}$ assimilation into AA (e.g., glutamate dehydrogenase or alanine dehydrogenase), integrating VFA profile with the increasing bacterial $\mathrm{N}$ being derived from $\mathrm{NH}_{3}-\mathrm{N}$ (Table 2).

The decrease in total VFA production without a concurrent decrease in OM digestibility indicates a shift in the flux of the carbon skeletons. Balancing of carbon for catabolic and anabolic reactions is well described for anaerobic microbes (Russell and Wallace, 1988). For example, Karnati et al. (2009a) discussed a shift in flux of glucose carbon toward de novo synthesis of FA and diverted from VFA production after defaunating continuous cultures. In another study from our laboratory (Firkins et al., 2015), we provide evidence that increasing $\mathrm{HMBi}$ supplementation increasingly accumulated free Met in fermenter fluid, even though DL-Met dosage decreased. Because the free Met was not incorporated into bacterial protein, we surmised that Met degradation decreased (as supported by the increasing peptide concentration in Table 2, which includes free AA) or else more Met and other AA were fermented to products other than VFA (and not measured in the current study). All of these responses can explain decreased VFA production without concomitant decrease in true OM digestibility. The decreased NDF digestibility without a decrease in $\mathrm{OM}$ digestibility for increasing HMBi might be a result of a competition by amylolytic bacteria (NSC was not measured but is the missing component of $\mathrm{OM}$ ) versus hemicellulolytic bacteria for preformed AA in our low-RDP diets (Table 1). We also note that OM digestibility is peculiarly low in continuous culture (Hristov et al., 2012), perhaps because of 
Table 3. Volatile FA production per day for rumen bacteria in continuous culture supplemented with DL-Met, HMBi ${ }^{1}$, or both (Experiment 1$)$

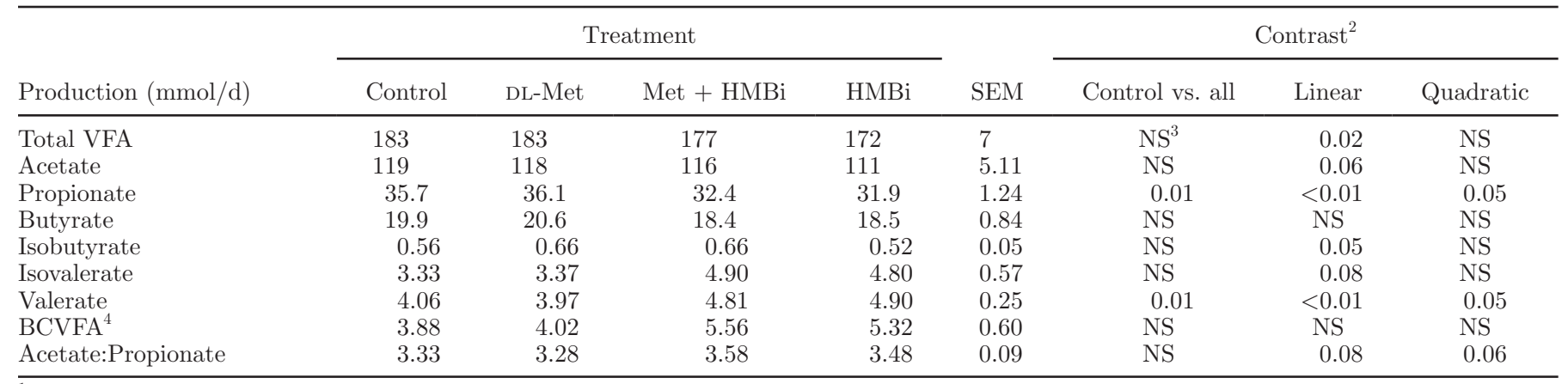

${ }^{1} \mathrm{HMBi}=2$-hydroxy-4-(methylthio) butanoic acid.

${ }^{2}$ All supplementation (DL-Met, Met $+\mathrm{HMBi}, \mathrm{HMBi}$ ) vs. control.

${ }^{3} \mathrm{NS}=$ not significant; $P>0.10$.

${ }^{4} \mathrm{BCVFA}=$ branched-chain VFA, which includes isobutyrate and isovalerate.

the large amount of buffer infusion to compensate for no VFA absorption.

Increased Met supplementation through protein sources in continuous culture has had no effect on total or individual VFA but increased AA outflow (Bach and Stern, 1999). When comparing HMB, HMBi, and DL-Met in vivo, no differences in VFA concentration were observed (Noftsger et al., 2005), but supplementing HMB in continuous culture increased isobutyrate and decreased propionate production (Noftsger et al., 2003). Continuous culture allows measurement of VFA production, whereas VFA absorption rates could vary among VFA in vivo.

Bacterial Population as Assessed by Denaturing Gradient Gel Electrophoresis Banding. The dendrogram in Figure 1 shows that bands cluster primarily by period, and no relative changes were noted in the abundance of the present populations associated with treatment. These lack of banding patterns contrasts with banding by Met source (including HMB) in the studies of Noftsger et al. (2003) in continuous culture and Karnati et al. (2007) in dairy cows. Although denaturing gradient gel electrophoresis only assesses abundant populations (Karnati et al., 2009b) and would presumably preclude the detection of the low-abundance/high-activity deaminating populations of bacteria, the current results suggest that differences among treatments were a result of shifts in metabolic activity, not major shifts in bacterial population structure.

\section{Experiment 2: Batch Culture of Met and Met Analogs}

Protozoal Counts. Samples of inocula collected the morning of batch culture inoculation contained an average of 23,740 protozoal cells/mL in faunated inocula, which was about 9 times greater than those in the defaunated inocula (average of 2,670 protozoal/ $\mathrm{mL}$ ). The predominant protozoa in the defaunated inoculum were small Entodinium species, which are more difficult to remove from continuous culture fermenters but also represent less activity because of their lower biomass compared with the larger protozoa. The highly abundant Entodinium caudatum is particularly bacterivorous and proteolytic compared with the larger protozoa, although differences probably are magnified in studies that used protozoal cells that previously had been starved (Diaz et al., 2014).

Enrichment of $\left[1-{ }^{13} C\right]-L-M e t$ in Microbial Protein. There were no interactions $(P>0.10)$ among faunation status and Met treatment or among time; thus, main effect means are presented in Table 4. Methionine enrichment of the pellet and associated calculations documented main effects of inoculum $(P<0.07)$, treatment $(P<0.07)$, and time $(P<0.05)$. Compared with the faunated inoculum, the partially defaunated inoculum (averaged over other effects in the model) increased the proportion of ${ }^{13} \mathrm{C}-$ Met dose incorporated into microbial Met, and this $10 \%$ difference increased to $21 \%$ for the incremental microbial Met derived from the dose (correcting for blanks). Protozoa can incorporate direct AA, but their preferred source is bacterial protein (Williams and Coleman, 1992). The quadratic responses to time documented peaks at $8 \mathrm{~h}$ as microbial protein synthesis increased uptake of preformed L-Met dose followed by decreases at $24 \mathrm{~h}$ as recycling of microbial Met diluted the label such that more Met was synthesized de novo (perhaps by microbes growing on the more slowly degraded fiber).

The control treatment had the numerically highest APE and percentage of label inclusion in total microbial Met because there was no other supplemental Met 


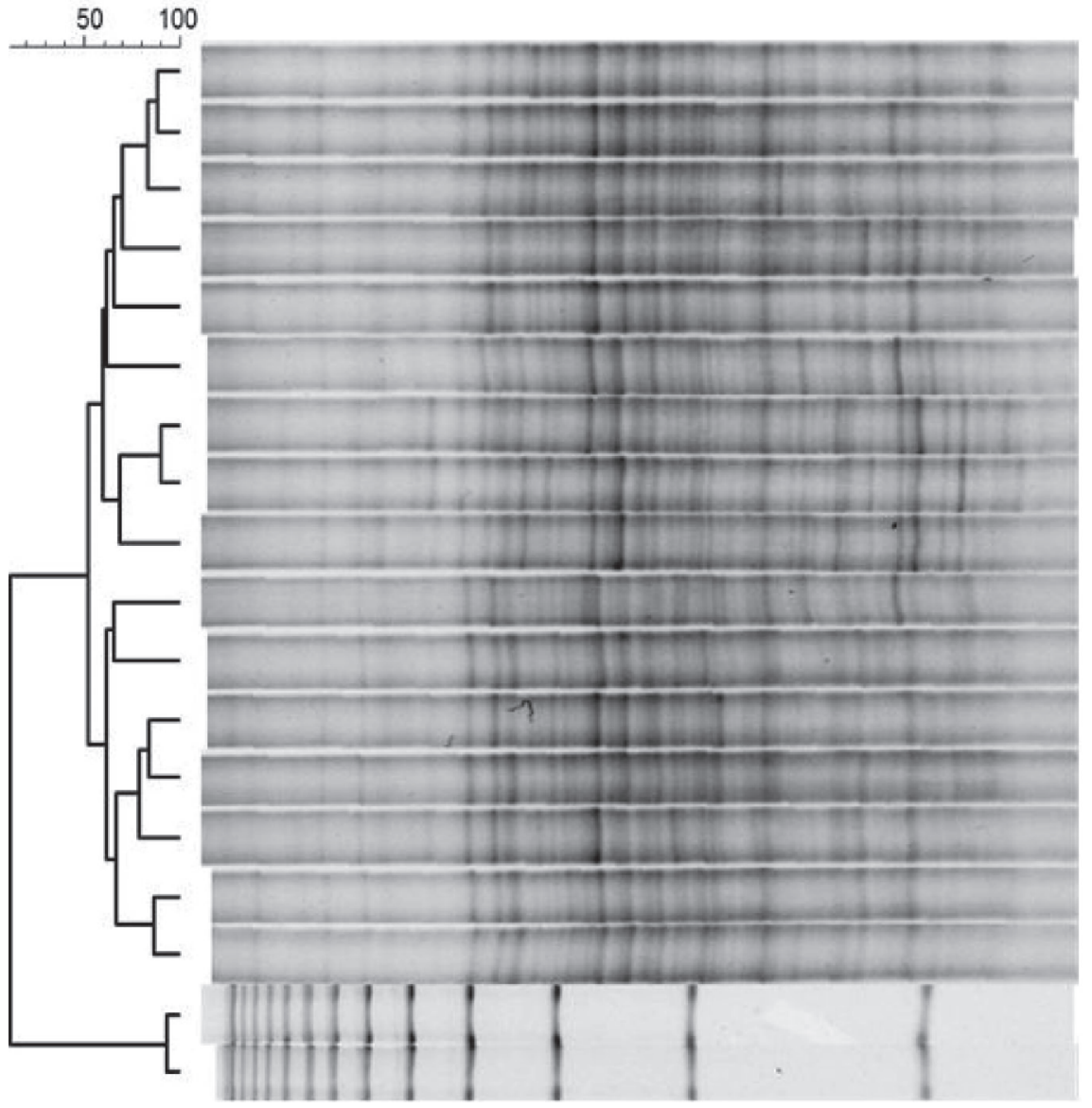

$\mathrm{P} 2 \mathrm{HMBi}$

P2 CON

P2 $\mathrm{HMBi}+\mathrm{MET}$

P2 MET

P3 MET

P1 CON

P1 HMBi

P1 HMBi+MET

P1 MET

P3 HMBi+MET

P4 CON

P3 CON

P4 HMBi

P3 $\mathrm{HMBi}$

P4 MET

P4 HMBi+MET

Marker

Marker

Figure 1. Comparison of the bacterial community structure from continuous culture samples; dendrogram shows cluster analysis that was performed using the Jaccard method; $\mathrm{P}=$ period 1 to $4 ; \mathrm{HMBi}=2$-hydroxy-4-(methylthio) butanoic acid isopropyl ester; CON $=$ control; MET $=$ DL-Met; and $\mathrm{HMBi}+\mathrm{MET}=50: 50$ mixture of HMBi and MET. The length of scale depicts the percentage similarity between different lanes.

source to dilute the $\left[1-{ }^{13} \mathrm{C}\right]$-L-Met label that was included in equal doses in all treatments (Table 4). The L-Met treatment decreased $(P<0.05)$ the APE of ${ }^{13} \mathrm{C}$-Met in the pellet through dilution compared with the control treatment because the unlabeled L-Met provided about $90 \%$ of the total dosed L-Met (including both the unlabeled L-Met treatment plus the $\left[1-{ }^{13} \mathrm{C}\right]$-L-Met label). The D-Met treatment was lower $(P<0.05)$ than the control but higher than the L-Met treatment. Thus, the D-Met treatment slowed bacterial incorporation of the $\left[1-{ }^{13} \mathrm{C}\right]$-L-Met dose into bacterial protein while the D-Met was undergoing stereoisomerization, but the lack of treatment by time interaction suggests a residual response (lack of compensation) compared with control. Firkins et al. (2015) discussed how D-Met might accumulate in periplasmic contents and decrease uptake of L-Met into cytoplasm. The L-Met versus D-Met comparison lost significance for incremental microbial Met because of this calculation's higher variability relative to the means.
The HMB and HMBi treatments had no effect on enrichment of bacterial Met (Table 4). That their results more closely resemble those of D-Met than those of L-Met suggests a more similar action between D-Met and the DL-HMB and DL-HMBi analogs compared with L-Met. However, no way of distinguishing the response exists because the precursor free Met could not be recovered (degraded during storage). The HMBi did increase $(P<0.05)$ the APE of bacterial Met compared with HMB, suggesting greater breakdown of HMB into the free Met precursor to dilute the APE of microbial Met compared with HMBi.

Assuming HMB and HMBi were one-half D-stereoisomers (Lobley et al., 2006), those treatments' responses are expected to be halfway between the L-Met and DMet treatments (Table 4). When DL-Met was added to HMBi (half dosages each to make a combined equimolar dose), the APE was decreased intermediate between the L-Met and D-Met treatments. Numerical interpolation of the APE results suggests that HMB was about 


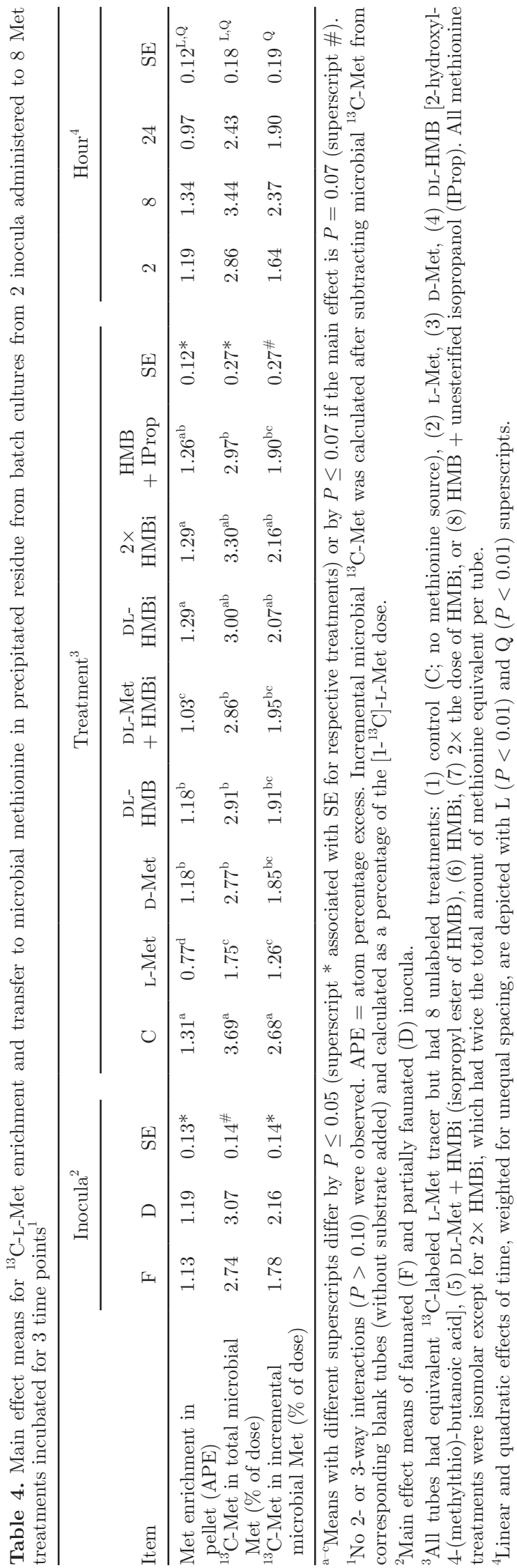

as inert as D-Met, but less inert than HMBi. Doubling the HMBi had no response, suggesting no saturation effect on $\left[1-{ }^{13} \mathrm{C}\right]$-L-Met metabolism.

Our hypotheses that HMBi conversion to Met could be offset by including a greater quantity of HMBi or that adding isopropanol would inhibit incorporation of Met into protein were not supported. However, the above responses do support HMB being more extensively degraded in the rumen than HMBi (Noftsger et al., 2005; Martin et al., 2013). Our responses also suggest that D-stereoisomers of Met and Met analogs do decrease the incorporation of preformed L-Met into microbial protein.

\section{CONCLUSIONS}

Preformed Met supply (directly or through HMB conversion) appeared to influence the activity of hemicellulose-degrading bacteria in continuous culture. Increased supplementation of HMBi increased the flow of free peptides and AA but decreased the net production of total VFA, indicating that carbon was being used for synthesis of AA rather than using preformed AA. Batch culture dosage of $\left[1-{ }^{13} \mathrm{C}\right]$-L-Met documented a decreased uptake of the label into bacterial protein, as influenced by supplying D-Met directly or through its precursor, HMB (or HMBi that is partially hydrolyzed to HMB). Isopropanol and doubling the HMBi had little effect on the rate of L-Met incorporation into microbial N, suggesting that differences were a result of HMBi being less degraded than HMB or D-Met.

\section{ACKNOWLEDGMENTS}

Research was supported by state and federal funds appropriated to the Ohio Agricultural Research and Development Center, The Ohio State University. Research funds were provided by Adisseo Inc. Manuscript number 09/14AS. The authors appreciate the skilled help of Sanjay Karnati (Procter and Gamble, Cincinnati, $\mathrm{OH}$ ) for help with fermenters and Zhongtang $\mathrm{Yu}$ and Lingling Wang (both of Department of Animal Sciences at The Ohio State University, Columbus) for help with DGGE analyses.

\section{REFERENCES}

AOAC. 1990. Official Methods of Analysis. 15th ed. AOAC, Arlington, VA.

Bach, A., and M. D. Stern. 1999. Effects of different levels of methionine and ruminally undegradable protein on the amino acid profile of effluent from continuous culture fermenters. J. Anim. Sci. 77:3377-3384.

Cava, F., M. A. de Pedro, H. Lam, B. M. Davis, and M. K. Waldor. 2011. Distinct pathways for modification of the bacterial cell wall by non-canonical D-amino acids. EMBO J. 30:3442-3453. 
Chaney, A. L., and E. P. Marbach. 1962. Modified reagents for determination of urea and ammonia. Clin. Chem. 8:130-132.

Clark, J. H., T. H. Klusmeyer, and M. R. Cameron. 1992. Microbial protein synthesis and flows of nitrogen fractions to the duodenum of dairy cows. J. Dairy Sci. 75:2304-2323.

Dehority, B. A. 1984. Evaluation of subsampling and fixation procedures used for counting rumen protozoa. Appl. Environ. Microbiol. 48:182-185.

Diaz, H. L., K. N. Barr, K. R. Godden, J. E. Plank, I. Zapata, A. N. Schappacher, W. P. Wick, and J. L. Firkins. 2014. Eukaryotic inhibitors or activators elicit responses to chemosensory compounds by ruminal isotrichid and entodiniomorphid protozoa. J. Dairy Sci. 97:2254-2269.

Ezeji, T., C. Milne, D. Price, and H. P. Blaschek. 2010. Achievements and perspectives to overcome the poor solvent resistance in acetone and butanol-producing microorganisms. Appl. Microbiol. Biotechnol. 85:1697-1712.

Firkins, J. L. 1997. Effects of feeding nonforage fiber sources on site of fiber digestion. J. Dairy Sci. 80:1426-1437.

Firkins, J. L., C. M. Fowler, B. J. Bequette, and E. Devillard. 2015. Kinetics of microbial methionine metabolism in continuous cultures administered different methionine sources. J. Dairy Sci. 98:1178-1194. http://dx.doi.org/10.3168/jds.2014-8694.

Firkins, J. L., A. N. Hristov, M. B. Hall, G. A. Varga, and N. R. StPierre. 2006. Integration of ruminal metabolism in dairy cattle. J. Dairy Sci. 89(E. Suppl.):E31-E51.

Firkins, J. L., Z. Yu, and M. Morrison. 2007. Ruminal nitrogen metabolism: Perspectives for integration of microbiology and nutrition for dairy. J. Dairy Sci. 90(E. Suppl.):1-16.

Griswold, K. E., G. A. Apgar, J. Bouton, and J. L. Firkins. 2003. Effects of urea infusion and ruminal degradable protein concentration on microbial growth, digestibility, and fermentation in continuous culture. J. Anim. Sci. 81:329-336.

Hackstein, J. H. P., and A. G. M. Tielens. 2010. Hydrogenosomes. Pages 175-206 in (Endo)symbiotic Methanogenic Archaea. J. H. P. Hackstein, ed. Springer-Verlag, Heidelberg, Germany.

Harvatine, D. I., J. L. Firkins, and M. L. Eastridge. 2002. Whole linted cottonseed as a forage substitute fed with ground or steam-flaked corn: Digestibility and performance. J. Dairy Sci. 85:1976-1987.

Hegedüs, M., S. Fekete, T. Veresegyházy, E. Andrásofszky, and E. Brydl. 1995. Effect of methionine and its related compounds on rumen bacterial activity. Arch. Tierernahr. 47:287-294.

Hoover, W. H. 1986. Chemical factors involved in ruminal fiber digestion. J. Dairy Sci. 69:2755-2766.

Hristov, A. N., C. Lee, R. Hristova, P. Huhtanen, and J. L. Firkins. 2012. A meta-analysis of variability in continuous-culture ruminal fermentation and digestibility data. J. Dairy Sci. 95:5299-5307.

Jensen, C., M. R. Weisbjerg, and T. Hvelplund. 2006. Evaluation of methods for estimating the amino acid supply to the duodenum of microbial, endogenous, and undegraded feed protein on maize silage diets fed to dairy cows. Anim. Feed Sci. Technol. 131:1-24.

Karnati, S. K. R., J. T. Sylvester, S. M. Noftsger, Z. Yu, N. R. StPierre, and J. L. Firkins. 2007. Assessment of ruminal bacterial populations and protozoal generation time in cows fed different methionine sources. J. Dairy Sci. 90:798-809.

Karnati, S. K. R., J. T. Sylvester, C. V. D. M. Ribeiro, L. E. Gilligan, and J. L. Firkins. 2009a. Investigating unsaturated fat, monensin, or bromoethanesulfonate in continuous cultures retaining ruminal protozoa. I. Fermentation, biohydrogenation, and microbial protein synthesis. J. Dairy Sci. 92:3849-3860.

Karnati, S. K. R., Z. Yu, and J. L. Firkins. 2009b. Investigating unsaturated fat, monensin, or bromoethanesulfonate in continuous cultures retaining ruminal protozoa. II. Interaction of treatment and presence of protozoa on prokaryotic communities. J. Dairy Sci. 92:3861-3873.

Korhonen, M., S. Ahvenjärvi, A. Vanhatalo, and P. Huhtanen. 2002. Supplementing barley or rapeseed meal to dairy cows fed grass-red cover silage: II. Amino acid profile of microbial fractions. J. Anim. Sci. 80:2188-2196.
Kristensen, N. B., A. Storm, B. M. L. Raun, B. A. Røjen, and D. L. Harmon. 2007. Metabolism of silage alcohols in lactating dairy cows. J. Dairy Sci. 90:1364-1377.

Lam, H., D.-C. Oh, F. Cava, C. N. Takacs, J. Clardy, M. A. de Pedro, and M. K. Waldor. 2009. D-Amino acids govern stationary phase cell wall remodeling in bacteria. Science 325:1552-1555.

Lobley, G. E., T. J. Wester, G. Holtrop, J. J. Dibner, D. S. Parker, and M. Vázquez-Añón. 2006. Absorption and digestive tract metabolism of 2-hydroxy-4-methylthiobutanoic acid in lambs. J. Dairy Sci. 89:3508-3521.

Martin, C. C. Mirande, D. P. Morgavi, E. Forano, E. Devillard, and P. Mosoni. 2013. Methionine analogues HMB and HMBi increase the abundance of cellulolytic bacterial representatives in the rumen of cattle with no direct effects on fibre degradation. Anim. Feed Sci. Technol. 182:16-24.

Martín-Venegas, R., M. T. Brufau, Y. Mercier, P.-A. Geraert, and R. Ferrer. 2011. Intestinal cell conversion of DL-2-hydroxy-(4-methylthio)butanoic acid in vitro: Dietary up-regulation by this methionine precursor. Br. J. Nutr. 106:350-356.

NRC. 2001. Nutrient Requirements of Dairy Cattle. 7th rev. ed. ed. Natl. Acad. Sci., Washington, DC.

Noftsger, S., N. R. St-Pierre, and J. T. Sylvester. 2005. Determination of rumen degradability and ruminal effects of three sources of methionine in lactating cows. J. Dairy Sci. 88:223-237.

Noftsger, S. M., N. R. St-Pierre, S. K. R. Karnati, and J. L. Firkins, 2003. Effects of 2-hydroxy-4-(methylthio) butanoic acid (HMB) on microbial growth in continuous culture. J. Dairy Sci. 86:26292636.

Russell, J. B., and R. J. Wallace. 1988. Energy yielding and consuming reactions. Pages 185-215 in The Rumen Microbial Ecosystem. P. N. Hobson, ed. Elsevier Applied Science, New York, NY.

Sato, H., and Y. Shiogama. 2010. Acetone and isopropanol in ruminal fluid and feces of lactating dairy cows. J. Vet. Med. Sci. $72: 297-300$

Schieber, A., H. Brückner, and J. R. Ling. 1999. GC-MS analysis of diaminopimelic acid stereoisomers and amino acid enantiomers in rumen bacteria. Biomed. Chromatogr. 13:46-50.

St-Pierre, N. R., and J. T. Sylvester. 2005. Effects of 2-hydroxy4-(methylthio) butanoic acid (HMB) and its isopropyl ester on milk production and composition by Holstein cows. J. Dairy Sci. 88:2487-2497.

Trabalza-Marinucci, M., C. Poncet, E. Delval, and G. Fonty. 2006. Evaluation of techniques to detach particle-associated microorganisms from rumen contents. Anim. Feed Sci. Technol. 125:1-16.

Van Soest, P. J., J. B. Robertson, and B. A. Lewis. 1991. Methods for dietary fiber, neutral detergent fiber, and nonstarch polysaccharides in relation to animal nutrition. J. Dairy Sci. 74:3583-3597.

Vázquez-Añón, M., T. Cassidy, P. McCullough, and G. A. Varga. 2001. Effects of Alimet on nutrient digestibility, bacterial protein synthesis, and ruminal disappearance during continuous culture. J. Dairy Sci. 84:159-166.

Volden, H., O. M. Harstad, and L. T. Mydland. 1999. Amino acid content and profile of protozoal and bacterial fractions isolated from ruminal contents of lactating dairy cows fed diets differing in nitrogen supplementation. Acta Agric. Scand. A Anim. Sci. $49: 245-250$.

Williams, A. G., and G. S. Coleman. 1992. The Rumen Protozoa. Springer-Verlag, New York, NY.

Yu, Z., and M. Morrison. 2004. Improved extraction of PCR-quality community DNA from digesta and fecal samples. Biotechniques $36: 808-812$

Zhang, Z., Z. N. Feige, A. B. Chang, I. J. Anderson, V. M. Brodianski, A. G. Vitreschak, M. S. Gelfand, and M. H. Saier Jr. 2003. A transporter of Escherichia coli specific for L- and D-methionine is the prototype for a new family within the $\mathrm{ABC}$ superfamily. Arch. Microbiol. 180:88-100. 